\title{
Let's play a new game: the drivers of eSports consumption
}

\author{
Vamos jogar um novo jogo: os motivadores do consumo de eSports \\ Juguemos a un nuevo juego: los impulsores del consumo de eSports
}

Received: 04/18/2021 | Reviewed: 04/23/2021 | Accept: 04/27/2021 | Published: 05/11/2021

\author{
Renan Leite dos Santos \\ ORCID: https://orcid.org/0000-0001-7132-2830 \\ Universidade Federal de Santa Catarina, Brazil \\ E-mail: renan.leite@posgrad.ufsc.br \\ Martin de La Martinière Petroll \\ ORCID: https://orcid.org/0000-0001-7280-9202 \\ Universidade Federal de Santa Catarina, Brazil \\ E-mail: martin.petroll@ufsc.br \\ Ricardo Boeing \\ ORCID: https://orcid.org/ 0000-0003-3320-0116 \\ University of Winsconsin, United States \\ E-mail: martin.petroll@ufsc.br \\ Fernanda Scussel \\ ORCID: https://orcid.org/ 0000-0001-7953-6710 \\ Universidade Federal de Santa Catarina, Brazil \\ E-mail: contatofernandascussel@gmail.com
}

\begin{abstract}
Despite the growth and economic relevance of electronic sports (eSports), the motivations of this type of media and entertainment consumption remain underexplored, particularly in scenarios in which traditional sports are a cultural element and an important influence in the lifestyle of the population. Thus, the main objective of this paper is to understand the drivers of electronic sports motivation for the Brazilian eSports audience, regarding their motivations to watch online matches. We performed a survey with 262 Brazilian eSports spectators, analyzing the results through Structural Equation Modeling. Findings revealed that that eSports consumption is driven by four main motivations, namely, novelty, escapism, aesthetic and vicarious achievement, being vicarious achievement the main driver of eSports consumption in Brazil. This study advances the understanding of the influence of culture in eSports consumption, exploring the antecedents of this kind of media entertainment and the role of motivations in the digital arena. This comprehension is paramount due to the increase of digital platforms, digital types of entertainment and the growth of eSports consumption worldwide.
\end{abstract}

Keywords: ESports; Electronic sports; Media consumption; Uses and gratifications theory.

\section{Resumo}

Apesar do aumento e relevância econômica dos jogos eletrônicos (eSports), as motivações para o consumo desse tipo de mídia continuam inexploradas, particularmente em contextos nos quais esportes tradicionais são um elemento cultural e um importante influenciador do estilo de vida da população. Portanto, o principal objetivo desse trabalho é compreender quais fatores são importantes no consumo de eSports no Brasil, relacionado a suas motivações para assistir partidas online. Foi realizado um survey com 262 espectadores de eSports brasileiros, analisado através de Equações Estruturais Modeladas. Os resultados indicam que são quatro os principais fomentadores, sendo eles, novidade, escapismo, estética e conquistas obtidas, sendo este o principal. Esse estudo avança na compreensão da influencia da cultura no consumo de eSports, explorando antecedentes desse tipo de consumo de entretenimento midiático e o papel dos motivadores na arena digital. Essa compreensão é primordial devido ao aumento das plataformas digital de entretenimento e o aumento do consumo de eSports no mundo.

Palavras-chave: ESports; Esportes eletrônicos; Consumo de mídia; Teoria dos usos e gratificações.

\section{Resumen}

A pesar del crecimiento y relevancia económica de los deportes electrónicos (eSports), las motivaciones de este tipo de consumo mediático y entretenimiento siguen sin ser exploradas, particularmente en contextos en que los deportes tradicionales son un elemento cultural y una influencia importante en el estilo de vida de la población. Por lo tanto, el objetivo principal de este artículo es comprender los impulsores de la motivación de los deportes electrónicos para la audiencia brasileña de eSports, en cuanto a sus motivaciones para ver partidos online. Realizamos um survey a 262 espectadores brasileños de eSports, analizando los resultados a través de Ecuaciones Estructurales Modeladas. Los resultados revelaron que el consumo de eSports está impulsado por cuatro fomentadores principales, a saber, novedad, escapismo, estética y logros obtenidos, siendo este el principal impulsor del consumo de eSports en Brasil. Este 
estudio avanza en la comprensión de la influencia de la cultura en el consumo de eSports, explorando los antecedentes de este tipo de entretenimiento mediático y el papel de las motivaciones en el ámbito digital. Esta comprensión es primordial debido al aumento de las plataformas digitales, los tipos de entretenimiento digital y el crecimiento del consumo de eSports en todo el mundo.

Palabras clave: ESports; Deportes electronicos; Consumo de medios; Teoría de usos y gratificación.

\section{Introduction}

Electronic sports (eSports) are organized video game competitions, recognized both as sports entertainment and as sport practice due to the requirement of physical and mental skills that enable consumers to compete in the digital field (Funk, Pizzo, \& Baker, 2018). In the recent years, eSports have turned into a lucrative industry like traditional sports, including players, teams, competitions, managers, leagues and organized crowds (Jenny, Manning, Keiper, \& Orlrich, 2017).

Despite its growth and economic relevance, literature holds a strong discussion about the legitimation of electronic sports as a sports practice (Jonasson \& Thiborg, 2010; Seo, 2013, 2016; Seo \& Jung, 2016). In this regard, several scholars have shown that eSports and traditional sports share the basic elements of sports as a social practice: eSports are physical, actors play by rules, it is competitive and this configuration follows the regulation of a specific official institution (Funk et al., 2018; Hallmann \& Giel, 2018; Heere, 2018). Additionally, eSports represent a huge market share of sports market (Taylor, 2012). According to Newzoo (2020), the global e-sport economy will generate revenues of 1.1 billion dollars (950.6 million in 2019), a year-on-year growth of $15.7 \%$. The global e-sport audience will reach 495.0 million this year.

Concerning the consumption of eSports, media appreciation on eSports is similar to traditional sports - even the ESPN $^{\circledR}$ website, a popular sports channel, has an entire session dedicated to eSports, with the same visibility and attention that other sports such as golf, tennis, MMA (mixed martial arts) and the Olympic Games (Pizzo et al., 2018). Literature signalizes studies dedicated to explore consumers' motivation on eSports (Gandolfi, 2016; Hamari \& Sjöblom, 2017; Pizzo et al., 2018), although only a few works investigated if eSports operate in the same manner as traditional sports (Hamari \& Sjöblom, 2017; Pizzo et al., 2018). Researchers have found that the drivers for e-sport consumption could be similar, nevertheless, due to the difference between genres of e-sport, media vehicles and social cultures, further research is required.

Pizzo et al. (2018) stated that eSports work similarly to traditional sports, but the behavior of its audience remains undertheorized. Traditional sports consumption is connected to the motivation one has to watch a game (Funk, Alexandris, \& McDonald, 2008), combining psychological and sociological needs that affect media consumption (Sullivan, Raney, \& Bryant, 2006). Hence, consumers resort to sports media to fulfill affective and social motivations, since emotions and socialization are associated to this kind of media consumption (Raney, 2006). Based in this, we wonder if these are the same motivations for eSports. Moreover, what are the motivations for eSports audience in cultures where sports is more than entertainment, but a tradition?

Considering the discussion above, we propose a replication of the work of Hamari and Sjöblom (2017) in Brazil, context in which sports are part of the culture and sports practice are encouraged since childhood, engendering an economic sector that raised Olympic winner teams, idols, soccer clubs and influences the lifestyle of the Brazilian population, especially regarding sports consumption.

Nations in development, such as Brazil, can present a lot of challenges for people who try to implement tactics well established in developed countries. The context is totally different and has its peculiarities, for that reason, Sheth (2011) argue that for the advance of the marketing science and practice, research on those contexts should be encouraged. In fact, this author suggests that marketing is a subject that is modified according to the conditions in which it is inserted. Therefore, this study contributes to marketing science and practice literature by questioning the global use of the aforementioned constructs, 
and examining the generalizations based on developed countries in the context of developing countries (Burgess \& Steenkamp, 2006).

With that in mind, our study replicates Hamari and Sjöblom (2017) work to confirm (or disconfirm) the stability and validity of their findings. As these scholars propose, we resort to the Uses and Gratifications Theory (U\&G) to investigate motivation, since its body of knowledge provides a good theoretical explanation for media usage and access. U\&G theory posit that persons look for channels of communication that better fulfill their needs and desires. Therefore, the objective of this article is to understand the drivers of electronic sports consumption for the Brazilian eSports audience, regarding their motivations to watch online matches.

\section{Methodology}

\subsection{ESports}

ESports are competitive video game communities that have become a new professional type of sport in the new era of gaming culture (Bányai, Griffiths, Király, \& Demetrovics, 2019). These communities started in South Korea, quickly reaching Asia and Western counties, especially among teenagers and young adults. The video gaming industry has started to be seen as sport once the focus of the gameplay was switched from person against machine to the people competing against each other, which lead to this new competition environment. (Griffiths, Davies, \& Chappell, 2003).

As proposed by Hallman and Giel (2018), eSports are a physical activity - the core element of a sport, having competition as the players' main motivation and engendering organizational structures. This context has created an industry with professional players, tournaments, systems, and media broadcasting (Taylor, 2012), sponsors, organizers, championships and specialized audiences (Bányai et al., 2019), the same way as traditional sports.

Research on eSports has covered advertising in the games, the so-called advergames (Quilliam, Lee, Cole, \& Kim, 2011), flow experience (Ham, Yoon, \& Nelson, 2016; Vanwesenbeeck, Ponnet, \& Walrave, 2016), online identity construction (Costa Pinto, Reale, Segabinazzi, \& Vargas Rossi, 2015) and relationship with brands (Kim, Choi, Kim, \& Liu, 2015). Literature covers studies about the interactions between eSports consumers in online communities, concerning online socialization De Mello \& Mastrocola, 2014; Molesworth, Watkins, \& Denegri-Knott, 2016).

An important research stream concerns the motivation of eSports consumers. Pizzo et al. (2018) postulate that traditional sport and eSports audiences share the same consumption motives, namely, interest in sport, interest in player, esthetics, social opportunities, drama, role model, entertainment value, wholesome environment, acquisition ok knowledge, skill of the athletes and enjoyment of aggression.

In addition, researchers have found that experiencing the broadcast in real time and the opportunity for social interaction are important factors for the consumers (Hamilton, Garretson \& Kerne, 2014; Scholz, 2012). Acquiring knowledge has been shown to be one of the most relevant factors when it comes to video game streaming (Hamilton et al., 2014; Cheung \& Huang, 2011). Those, in conjunction with entertainment, are the two major roles when it comes to consuming media related to the eSports (Ferguson \& Perse, 2000; Cha, 2014; Hanson \& Haridakis, 2008; Shao, 2009).

However, place eSports in the same category of sports media consumption, such as soccer or basketball, seems counterintuitive, because this new sport still lacks establishment in our society and, for that reason, Sjöblom, Macey \& Hamari, (2019a) argue that it should this new type of consumption should be investigated.

All things considered, further research need to be done on the subject. Most of eSports consumption occurs through platforms such as Twitch and YouTube (Taylor, 2018), but very little is known in how the traditional media can play a role in that scenario. Also, since the eSports are electronic media in its essence, how the established parts in sport consumption such as consumers and producers operates in this new environment (Sjöblom, Törhönen, Hamari, \& Macey, 2019b). 
Considering the above, we note that previous research endeavors that the choice for consuming this type of media is a multifaceted problem, in which a variety of motivational factors plays a role.

\subsection{Uses and gratifications theory}

The Uses and Gratifications Theory (U\&G) is a useful theoretical background to understand media technologies consumption in consumers' perspectives (Ruggiero, 2000). The main objective of uses and gratification theory is to explain the psychological needs that shape why people use the media and that motivates them to engage in certain media-use behaviors for gratifications that fulfill intrinsic needs (Rubin, 1994). That being said, most of the research utilizing $U \& G$ has been conducted in order to better comprehend the gratifications received by media consumption (So, 2012).

As stated by West and Turner (2006), the U\&G Theory states that users are aware of their own usage, which enables them to provide researchers a precise idea of their habits and motivations for media consumption. Several studies prove its efficacy, since the U\&G Theory has been the choice of investigations about online consumption (Papacharissi \& Mendelson, 2010; Whiting \& Williams, 2013), online games (Wu, Wang \& Tsai, 2010), video streaming (Cha, 2014), fantasy sports (Farquhar \& Meeds, 2007) and eSports (Hamari \& Sjöblom, 2017).

Recent research using the U\&G postulate that behaviors are shaped by social and psychological factors, which interfere in media usage (Rubin, 2009). Considering that the major part of eSports consumptions happens through streaming platforms, U\&G Theory has been chosen as the theoretical lens of this study, in attempt to better understand the drivers of eSports consumption. As a technique of research, we opted by the survey, since it is possible to collect a big amount of data without the influence of the researchers (Hair, Babin, Money, \& Samouel, 2003). The next section discusses this work's hypothesis formulation.

\subsection{Hypothesis Development}

According to Southern (2017), traditional sports audience is motivated by emotional, cognitive and behavioral motivations, while the experiential aspects of the game motivate eSports audience. This means that the environment plays a relevant role in eSports consumption. As reported by this scholar, the spectator of eSports involves a stage with a large screen on which participants watch the game, creating an emotional experience around the matches, context in which the emotional drama is associated to satisfaction.

One important motivation for consumption of eSports is called drama. Accordingly to Sjöblom et al., (2019a) this is associated with the big turnarounds that can happen during matches, leading to arousal and excitement of the public. That feeling can be amplified when experienced in live events (Taylor, 2012; Weed, 2006). However, for mediated sports consumption, higher levels of drama, result in a more amusement experience (Peterson and Raney, 2008; Raney and Depalma, 2006). Based on these arguments, we present our first hypothesis:

Hypothesis 1 - Drama drives spectators to consume eSports.

Fandom in sports is a heavily emotional act (Taylor, 2012). Such emotions are linked to the connection between fans and team, which lead to the spectators having a personal satisfaction when their team wins. That is called by the literature as vicarious achievement (Trail, Anderson, \& Fink, 2000). This motivation is responsible for the public demonstrations of association such as attending live sporting events (Dionísio, Leal, \& Moutinho, 2008) or the manifestation in social platforms.

Hamari and Sjöblom (2017) indicate that streaming made by esport players can foster the connection between spectators, teams and idols. As the authors propose, such connection creates a strong bond between them, generating intense 
feelings during the games: the victory of the teams is seen as their own achievement. From this, we understand that eSports consumers watch the games to cheers for their idols, raising the second hypothesis of this article:

Hypothesis 2 - Vicarious achievement drives spectators to consume eSports.

The context of online gaming dialogues with the experiential perspective, brought by Pine, Pine, and Gilmore (1999) and Pine and Gilmore (2013) as the new economic paradigm, in which the economic development is created by the value derived from consumers' experience, in contrast with the acquisition of products. In this perspective, literature signalizes consumers embrace consumption experiences as a way to escape routine and the rules, norms and obligations of everyday life (Arnould \& Price, 1993; Goulding, Shankar, Elliott, \& Canniford, 2009; Skandalis, Byrom, \& Banister, 2019).

As Seo (2013) proposes, the online gaming context is in alignment with such approach, as the active participation and immersion of consumers in electronic sports promote a sense of escape, being experiential value an important element of this growing industry. This economic model focuses on giving consumers an experience of memorable events in exchange for money (Pine \& Gilmore, 2013), and Seo (2013) explains that e-sport consumers follow this economic model.

Studies have pointed out escape as one of the reasons people watch sports games, considering this consumption as a break from routine and the obligations of daily life (Wann, Allen, \& Rochelle, 2004). Besides, escape is strongly related to video game consumption (Beranuy, Carbonell, \& Griffiths, 2013), leading us to explore the connection between the escape experience and eSports consumption. It is also known that media consumption promoted this sense of escape consumers are seeking for (Papacharissi \& Mendelson, 2010; Whiting \& Williams, 2013), leading us to believe that the participation in electronic games context holds an experiential dimension. Based on this idea, the third hypothesis has been proposed.

Hypothesis 3 - Escape drives spectators to consume eSports.

So far, we have explored the emotional perspective of sports; however, this activity is not limited to an emotional experience, since the audience also receive cognitive stimuli (Raney, 2006). In this respect, as Raney (2006) proposes, knowledge acquisition is one of the most known cognitive motives that lead consumers to watch games, as they try to learn about the players, the teams and the game dynamics. This learning process is commonly associated to the consumers' favorite team, and the knowledge about it can be used as a social asset in future interactions.

Following these ideas, it is plausible to say media consumption is an opportunity for acquisition of knowledge. This has been proved efficient in the context of videogames (Hamilton et al., 2014), social media (Papacharissi \& Mendelson, 2010; Whiting \& Williams, 2013) and internet use (Yuan, Lin, \& Zhuo, 2016). Thus, knowledge search, acquisition, and online shared boosts communities, and enhance consumer disposition to a practice. According to Hamari and Sjöblom (2017), media consumption is a way of acquisition of knowledge. Considering the above, we propose the following hypothesis.

Hypothesis 4 - Acquisition of knowledge drives spectators to consume eSports.

The esthetics part of sports has been shown to be relevant for sport consumption, this can be defined as the beauty or gracefulness inherent in sports games (Trail \& James, 2001; Xiao, 2020). Accordingly to Raney (2006) this motive can be very different when it comes to gender preferences. Men were found to like more aggressive sports like boxe or soccer, while women, has been shown a greater preference for more artistic sports, such as gymnastics or ice-skating. This esthetic motivation has proved to affect the context of eSports (Cheung \& Huang, 2011), videogame streaming (Hamilton et al., 2014) and social media (Papacharissi \& Mendelson, 2010; Whiting \& Williams, 2013).

The gaming industry has devoted a lot of resources in order to have games with well-designed graphics, providing viewers with an esthetically appealing experience (Xiao, 2020). Those better graphics qualities can lead to a far more 
enjoyable experience for the audience, since it can lead them to a more immersive involvement into the match. Curley, Nausha, Slocum, and Lombardi (2016) conclude that spectator's experience involves not only the game itself, but also how the eSports media content is created and presented to them. The esthetics construct pertains to the core art vision of the game - character design, environments, and animations - that is solidified prior to release.

According to Sjöblom et al. (2019a), this can be an important driver, especially in the online environment. Xiao (2020), for example, found a positive correlation between esthetics and attitude toward watching eSports. Considering the fact that eSports content is visual, mediated by human-computer interface, we hypothesize the following:

Hypothesis 5 - Esthetics drives spectators to consume eSports.

We must address, in the context of eSports, the skills and competence of the players. Literature has long ago signaled that players' skills, especially when creating difficult level moves, can be a motivation for sports consumption (Milne \& McDonald, 1999). Since spectators of eSports are also players, meaning they can watch the games to admire other players' skills, or even learn about new techniques (Hamari \& Sjöblom, 2017), we suggest the sixth hypothesis of the study:

Hypothesis 6 - Skills of the players/athletes drives spectators to consume eSports.

According to Sjöblom et al. (2019a), there are some motivational aspects to effectively predict sports consumption in multiple areas of regular sports, such as physical attractiveness (which is the outward beauty). When it comes to eSports, when analyzing other factors that might motivate spectators to consume them, Wohn and Freeman (2020) suggested that there might be certain eSports streamers that for whom physical attractiveness is a primary reason why they would receive money. Yu, Bennett and Brison (2019) concluded in their research that eSports marketers would benefit from highlighting the physical attractiveness when marketing to some fans.

Hamari and Sjöblom (2017) also concluded that eSports' players' physical attractiveness can also be a motivation for this kind of media consumption. This construct is associated with physical appearance of the players, because of the effort put into physical shape to deliver performance, which is driven by the context of competition. The outcome of such dedication is a physical level above the average (Hamari \& Sjöblom, 2017). Based on this, we propose the next hypothesis.

Hypothesis 7 - Physical attractiveness drives spectators to consume eSports.

Previous research found a variety of motivations for why people watch eSports, such as novelty, when studying the viewer needs and consumer practices (Weiss \& Schiele, 2013; Hamari \& Sjöblom, 2017). Arthur and Stuart (2014) argued that the gaming community and the demand for novelty and quality in games were one of the main driving motives behind the evolution of technologies linked to computers and information technology in general.

As stated in the work of Trail and James (2001), watching to new teams of sports is one of the main drivers of sports motivation. Similarly, Hamari and Sjöblom (2017) suggest that the rising of new teams and talents in this new modality may contribute to the gratification obtained by consumers of this type of media. In this sense, we developed the following hypothesis:

Hypothesis 8 - Novelty drives spectators to consume eSports.

The pleasure in aggressiveness was evaluated as an important factor in the context of eSports (Hamari \& Sjöblom, 2017), where online spectators rate is higher than live attendees (Sjöblom et al., 2019a). One of the reasons may be that aggressiveness has become less visible in traditional sports during our modern times (Mangeloja, 2019). 
In this scenario, aggressiveness can be understood as the appreciation of watching aggressive behaviors in sports (Hamari \& Sjöblom, 2017) like witnessing aggressive/hostile behavior by the players (Bányai et al., 2019). This motivation is intimately related to the drama inherent to sports competition and the opportunity for people to release emotions when consuming this kind of media. Considering the relation between aggressive behavior appreciation and satisfaction with media consumption, we propose:

Hypothesis 9 - Enjoyment of aggressiveness drives spectators to consume eSports.

The last hypothesis of this article addresses the aspect of social behavior. In this particular case, we will explain about social interaction theory, popularly adopted to explain social behavior (Zhou et al., 2019). Social interaction is a fundamental need for human beings because people have a significant tendency to form interpersonal relationships (Zhou et al., 2019). In the case of eSports, "social interaction refers to the gratifications related to socializing with other media consumers" (Hamari $\&$ Sjöblom, 2017, p. 217). Since the games are watched online in a digital platform, social interaction can happen through these digital devices (Woermann \& Kirschener, 2015).

For example, Hamilton et al. (2014) found that live-streams are like virtual "thirdplaces" where communities form and grow, with viewers using chat rooms to converse, laugh, and joke with each other about content they are watching. This environment have been presented in previous research to be a facilitator to foster relationships, helping people find new friends (Zhu \& Chang, 2014) and building new groups (Miller, 2011). Bargh \& McKenna (2004) argue that those online groups can help people maintain a psychological well-being when they lack this type of assistance outside the virtual world.

Build those relationships can be difficult for those who suffer with social anxiety. In that case, engaging in online platforms for social interaction can be a replacement for the lack of real life interaction (Desjarlais \& Willoughby, 2010; Mazalin \& Klein, 2008). Those interactions have been show by Valkenburg \& Peter (2009) as a lower risk environment, helping people to deal with fear of rejection.

In our case, viewer-viewer interaction, which is also called peer interaction, refers to the interaction among a group of viewers. This discussion has conducted us to our final hypothesis:

Hypothesis 10 - Social interaction drives spectators to consume eSports.

\subsection{Method}

This article reports a quantitative research, in which a survey was performed with 262 Brazilian eSports spectators. The sample is mainly formed by men (88\%) between 16 and 25 years old (65\%), who spend on average 12 hours playing and 6 hours watching eSports weekly. Regarding media consumption, most of them consume eSports via streaming platforms (57\%), followed by video on demand (40\%) and television (3\%).

The research instrument was the Motivation Scale for Sport Consumption - MSSC Scale (Trail \& James, 2001), since it is reliable measure to analyze psychological factors related to sports consumption, as previous studies report its efficacy (Funk \& James, 2006; James \& Ridinger, 2002; Robinson, Trail, \& Kwon, 2004; Robinson \& Trail, 2005; Seo \& Green, 2008; Trail \& James, 2001; Won \& Kitamura, 2007).

Since the original scale is in English and the research was conducted with Portuguese language speakers, we followed Brislin's (1970) instructions for back-translation. A native Portuguese speaker fluent in English translated the original instrument to Portuguese. In the next stage, the Portuguese version was translated to English by another researcher. The outcome of this phase was two instruments in English language. A third researcher compared both instruments, indicating the correspondence between them. According to Brislin (1970), this confirmation enables us to use the Portuguese version, as it semantically corresponds to the original scale. 
The MSSC Scale is formed by 31 items distributed in the following factors: achievement, esthetics, drama, escapism, knowledge acquisition, skills of the players, social interaction, physical attractiveness, novelty and appreciation of aggressiveness. All the items were measured using a Likert scale of seven points (1=totally disagree; $7=$ totally agree).

We performed a pre-test phase with 20 subjects in order to analyze the adequacy of the research instrument to our sample. No modifications were necessary. Thus, the instrument was shared in Brazilian eSports specialized online forums, eSports Facebook communities and eSports Whatsapp groups with an invitation to join the research. The questionnaire was available in the Google forms platform

Structural Equation Modeling (SEM), a technique that helps to explain the relations between multiple variables (Hair Jr, Hult, Ringle, \& Sarstedt, 2016), was used for data analysis. Moreover, Kline (2011) defends there are benefits in hypotheses testing using SEM, since it enables the researcher to access a more assertive statistical correspondence, increasing the reliability in accepting or rejecting a hypothesis. In this article, we performed the PLS-SEM (Partial Least Square - Structural Equation Modeling), which is the most recommended method when the research objective covers prediction testing (Hair et al., 2016). We have used the software SmartPLS® version 3.0.

We collected data from 280 questionnaires. The first step before performing SEM was data treatment, in which we identified missing values and outliers, following the guidance of Hair et al. (2016). No missing values were found. Regarding outliers, Hair et al. (2016) recommend the multivariate detection of atypical observations by calculating the Mahalanobis distance, at a conservative level of $\mathrm{p}<0.001$, indicating 18 outliers. Thus, the final sample of the article was 262 participants.

\section{Results and Discussion}

Literature shows that structural equation modeling is formed by two elements: (i) the measurement model, which enables the confirmatory check of the variables in the model and (ii) the structural model, in reference to the path connecting dependent and independent variables (Hair et al., 2016; Kline, 2011).

Hair et al. (2016) explain that the measurement model is the first step into a complete analysis of the structural model, suggesting the test of convergent validity, discriminant validity and reliability of the items of the research instrument. Convergent validity represents the extension in which a measure positively relates to the other measures of a construct. In accordance with Fornell and Larcker (1981), convergent validity can be confirmed through Average Variance Extracted (AVE) when its result is superior to 0.50 , revealing a satisfactory result for the model.

In this respect, results confirm convergent validity, as all the constructs of the research instrument have reached AVE's values above 0.5 (vicarious achievement $=0.89$; esthetics $=0.81 ;$ drama $=0.61$; escapism $=0.85 ;$ knowledge acquisition $=0.82$; skills of the players $=0.63$; social interaction $=0.91$; physical attractiveness $=0.81$; novelty $=0.92$; appreciation of aggressiveness $=0.66$ ).

For its turn, reliability demonstrates the consistency of the instrument in measuring a variable, and it can be analyzed accessing Cronbach's Alpha for each factor load and the compound reliability (Hair et al., 2016). Compound values between 0.6 and 0.7 are considered adequate and above 0.7 they are satisfactory. In the case of Cronbach's Alpha, Hair et al. (2016) expect reliable factors reach 0.7 . Table 1 presents the results, confirming the reliability of the variables in this study. 
Table 1. Reliability.

\begin{tabular}{|c|c|c|c|}
\hline Constructs & Items & Cronbach's Alpha & Compound Reliability \\
\hline \multirow{3}{*}{ Vicarious Achievement } & ACHB1 & 0,95 & \multirow{3}{*}{0,93} \\
\hline & $\mathrm{ACH} 2$ & 0,94 & \\
\hline & $\mathrm{ACH} 3$ & 0,94 & \\
\hline \multirow{3}{*}{ Esthetics } & AES4 & 0,92 & \multirow{3}{*}{0,88} \\
\hline & AES5 & 0,91 & \\
\hline & AES6 & 0,86 & \\
\hline \multirow{3}{*}{ Drama } & DRA7 & 0,85 & \multirow{3}{*}{0,67} \\
\hline & DRA8 & 0,83 & \\
\hline & DRA9 & 0,67 & \\
\hline \multirow{3}{*}{ Escapism } & ECP10 & 0,92 & \multirow{3}{*}{0,91} \\
\hline & ECP11 & 0,92 & \\
\hline & ECP12 & 0,93 & \\
\hline \multirow{3}{*}{ Knowledge Acquisition } & AQC13 & 0,89 & \multirow{3}{*}{0,89} \\
\hline & AQC14 & 0,92 & \\
\hline & AQC15 & 0,91 & \\
\hline \multirow{3}{*}{ Skills of the players } & SKL16 & 0,78 & \multirow{3}{*}{0,7} \\
\hline & SKL17 & 0,82 & \\
\hline & SKL18 & 0,77 & \\
\hline \multirow{3}{*}{ Social interaction } & SOC22 & 0,94 & \multirow{3}{*}{0,94} \\
\hline & SOC23 & 0,96 & \\
\hline & SOC24 & 0,96 & \\
\hline \multirow{3}{*}{ Physical attractiveness } & ATRA22 & 0,87 & \multirow{3}{*}{0,88} \\
\hline & ATRA23 & 0,92 & \\
\hline & ATRA24 & 0,91 & \\
\hline \multirow{3}{*}{ Novelty } & NVT25 & 0,93 & \multirow{3}{*}{0,95} \\
\hline & NVT26 & 0,97 & \\
\hline & NVT27 & 0,96 & \\
\hline \multirow{4}{*}{ Enjoyment of aggressiveness } & AGR28 & 0,79 & \multirow{4}{*}{0,83} \\
\hline & AGR29 & 0,74 & \\
\hline & AGR30 & 0,88 & \\
\hline & AGR31 & 0,84 & \\
\hline
\end{tabular}

Source: Authors (2021).

Moreover, reliability values over 0.7 indicate another trait of convergent validity (Hair et al., 2016), which is confirmed in almost every factor of our analysis (see Table 1) which the only exception of the construct Drama, that reveals a very close value (0.67) to 0.7. Hair et al. (2016) also state that factor loadings above 0.7 conform a third sign of convergent validity, explaining that items with loadings below this value should be eliminated since they do not contribute significantly to form the latent variable. When we analyze individually the factor loadings of the items (Table 1), all of them have values superior to 0.7, except the item DRA9 (0.67). However, we understand this item does not compromise the minimum value of the average variance extracted of the construct, and no item exclusion was necessary.

Lastly, discriminant validity analyzes how different the variables are, indicating that a variable is unique and measures what other measures are not able of measuring (Hair et al., 2016). To verify it, we resorted to the criteria recommended by Fornell and Larcker (1981): the Average Variance Extracted (AVE) of a construct must be higher than the shared variance of 
this construct with others. As Table 2 shows, since the quadratic values of the AVE's of the latent constructs are higher than the values of the correlations, discriminant validity is confirmed.

Table 2. Discriminant Validity.

\begin{tabular}{|c|c|c|c|c|c|c|c|c|c|c|}
\hline & AQC & ATR & $\mathrm{ACH}$ & DRA & ECP & AES & SKL & SOC & NVT & AGR \\
\hline Knowledge acquisition & 0,91 & & & & & & & & & \\
\hline Physical attractiveness & $-0,04$ & 0,9 & & & & & & & & \\
\hline Vicarious achievement & 0,293 & 0,078 & $\mathbf{0 , 9 5}$ & & & & & & & \\
\hline Drama & 0,167 & 0,126 & 0,149 & $\mathbf{0 , 8 7}$ & & & & & & \\
\hline Escapism & 0,332 & 0,155 & 0,404 & 0,21 & 0,92 & & & & & \\
\hline Esthetics & 0,311 & 0,09 & 0,464 & 0,306 & 0,473 & 0,9 & & & & \\
\hline Skills of the players & 0,413 & $-0,03$ & 0,283 & 0,286 & 0,152 & 0,224 & $\mathbf{0 , 7 9}$ & & & \\
\hline Social interaction & 0,287 & 0,083 & 0,343 & 0,135 & 0,262 & 0,254 & 0,2 & 0,95 & & \\
\hline Novelty & 0,301 & 0,112 & 0,337 & 0,189 & 0,307 & 0,322 & 0,267 & 0,307 & 0,96 & \\
\hline Enjoyment of aggressiveness & 0,089 & 0,282 & 0,079 & 0,025 & $-0,01$ & -0 & 0,066 & 0,112 & 0,111 & $\mathbf{0 , 8 1}$ \\
\hline
\end{tabular}

Note. In bold diagonal, there are the quadratic values of the AVE's of the latent constructs, which are superior to the values of the correlations with other constructs.

Source: Authors (2021) 
Based on the previous analysis, we confirm the measurement model reliability, convergent validity and discriminant validity, allowing us to follow the next steps, which is the exam of the structural model and the hypothesis test.

As proposed by Kline (2011), the structure model illustrates the relation between the variables and the effects they cause to each other. Kline (2011) and Hair et al. (2016) agree that the statistical results from a SEM must be interpreted by examining regression coefficients. First, there is the coefficient of determination $-\mathrm{R}^{2}$, which establishes the measure of the proportion of variance of the dependent variable around its mean, explained by the independent variables. Hair et al. (2016) suggest 0.25 is a weak value, 0.50 is medium and 0.75 is a substantial result for $\mathrm{R}^{2}$.

Second, there is the standardized coefficient or beta coefficient $-\beta$, representing the magnitude and the direction of the relationship between variables in a model, showing which variables are more important than the other in predicting a construct. The beta coefficient ranges between 0 and 1 , and the closer results are to 1 , higher the predictive power between variables.

To analyze the structural model in this study, we also evaluate the Variance Inflation Factor (VIF), an index that measures how much the variance of the estimated regression coefficient is increased by collinearity, and must result values under 5 (Hair et al., 2016). Regarding effect size, we examined Cohen's $\mathrm{F}^{2}$ method of effect size, according to Hair et al. (2016), who explain 0.02 is a small effect, 0.15 is a medium effect and 0.35 is a large effect. Lastly, besides evaluating the values of $R^{2}$ as predictive criteria, we verified the values of $Q^{2}$ of Stone-Geisser. In this case, Chin (1998) suggests a good model has relevance when $\mathrm{Q}^{2}$ presents values above zero.

Table 3 presents the results for the structural model analysis. 
Research, Society and Development, v. 10, n. 5, e40710515188, 2021

(CC BY 4.0) | ISSN 2525-3409 | DOI: http://dx.doi.org/10.33448/rsd-v10i5.15188

Table 3. Structural Model Analysis.

\begin{tabular}{|c|c|c|c|c|c|c|c|}
\hline Hypothesis & $\beta$ & Std. Dev. & T-statis. & $\mathrm{R}^{2}$ & $\mathrm{~F}^{2}$ & $\mathrm{Q}^{2}$ & FIV \\
\hline Drama $\rightarrow$ Motivation & 0,39 & 0,07 & $5,843 * *$ & 0,18 & 0,15 & 0,02 & 1,20 \\
\hline Vicarious Achievement $\rightarrow$ Motivation & 0,71 & 0,04 & $16,943 * *$ & 0,95 & 0,50 & 0,06 & 1,50 \\
\hline Escapism $\rightarrow$ Motivation & 0,67 & 0,05 & $14,725 * *$ & 0,82 & 0,45 & 0,05 & 1,49 \\
\hline Knowledgement acquisition $\rightarrow$ Motivation & 0,62 & 0,05 & $11,997 * *$ & 0,62 & 0,38 & 0,04 & 1,42 \\
\hline Esthetics $\rightarrow$ Motivation & 0,70 & 0,04 & $16,605^{* *}$ & 0,95 & 0,49 & 0,06 & 1,58 \\
\hline Skills of the players $\rightarrow$ Motivation & 0,50 & 0,07 & $7,476^{* *}$ & 0,33 & 0,25 & 0,02 & 1,34 \\
\hline Physical attractiveness $\rightarrow$ Motivation & 0,19 & 0,11 & 1,74 & 0,04 & 0,03 & 0,01 & 1,16 \\
\hline Novelty $\rightarrow$ Motivation & 0,65 & 0,06 & $12,799 * *$ & 0,71 & 0,41 & 0,05 & 1,30 \\
\hline Enjoyment of aggressiveness $\rightarrow$ Motivation & 0,17 & 0,09 & 1,11 & 0,03 & 0,02 & 0,00 & 1,13 \\
\hline Social interaction $\rightarrow$ Motivation & 0,59 & 0,06 & $9,890 * *$ & 0,52 & 0,34 & 0,04 & 1,24 \\
\hline
\end{tabular}

Note. $* *$ Relevant in confidence interval of $\mathrm{p}<0,01$

Source: Authors (2021). 
Table 3 indicates how much the structural model is able to predict the hypothesis previously proposed. All constructs were significant at $p<0.01$ with the exception of physical attractiveness and enjoyment of aggressiveness. All the other variables analyzed in Table 3 corroborate this finding. Therefore, we conclude that all of the motivations previously mentioned were significant drivers of eSports consumption.

The main purpose of this article is to understand the motivations traditionally related to sports consumption in the context of eSports.

The first hypothesis of the study aimed to understand the drama factor for eSports audience and it was confirmed. Our findings suggest drama is related to the eSports consumption; however, it has a weak effect on spectators' motivation, corroborating the original study of Hamari and Sjöblom (2017). Traditionally, sports audiences are connected to the enjoyment of uncertainty and dramatic developments during games, which have been a well-known driver of sports fans' media consumption (Raney, 2006).

Next, we analyzed the construct vicarious achievement, confirming the second hypothesis of this paper and indicating this as the most important driver of eSports consumption (see Table 3), also corroborating the findings of Hamari and Sjöblom (2017).

This motivation has been reported by researches to have a strong emotional factor, therefore, leading to high levels of loyalty and identification between teams, players and fans (Trail et al., 2000; Taylor, 2012).

In the following, escapism was analyzed, which has shown to be an important driver of eSports motivation, corroborating the work from Hamari and Sjöblom (2017) and confirming Hypothesis 3. As shown in previous research, vicarious achievement and escapism are important drivers for consumers of traditional sports (James \& Ross, 2004) and it appears to also be relevant to electronic sports (Baker, Zhou, Pizzo, Du, \& Funk, 2017).

The next step concerned acquisition of knowledge, another important driver of eSports consumption, also corroborating Hamari and Sjöblom's (2017) findings, enabling us to confirm Hypothesis 4. The relationship between the acquisition of knowledge and motivation for consumption can be linked to the profile of our sample, which has $82 \%$ of amateurs eSports players. In this sense, Taylor (2012) argues that players always start as spectators, moment used to understand the dynamics of the games, conforming a step for further participation. Hence, acquisition of knowledge seems to be a stage that eSports consumers go through before becoming players, an opportunity to build knowledge about the matches.

Esthetics has proved to be an important driver of eSports consumption as well, putting light into the visual aspects of the matches and the beauty of the sports' dynamic. However, our finding contradicts the results from the original work of Hamari and Sjöblom (2017), who affirm that esthetics is directly linked to the category of the sport, gymnastics for example. On the other hand, our results with the Brazilian sample shows aesthetic is a relevant factor in this type of consumption, confirming Hypothesis 5.

As for the skills of the players in the context of eSports, the results from Table 3 allow us to confirm Hypothesis 6, as there is a positive relation between skills of the players and the eSports consumption. According to Baker et al. (2017), this is an important motivation for eSports spectators.

The next topic of analysis was physical attractiveness. This has proved to be a motivation for traditional sports (Duncan \& Brummett, 1989; Guttmann, 1996), however, it does not apply in the context of eSports, leading us to reject Hypothesis 7 ( $\beta=0.194 ; \mathrm{T}=1.74$ e $\mathrm{F}=0.03$ ). The same result was found in the study of Hamari and Sjöblom (2017), confirming this variable is not related to eSports consumption. This can be justified due to the fact that the vast majority of participants in the present study are male and the e-sport scenario, in general, is composed mostly of teams made up of male players. Furthermore, due to the fact that electronic sports take place in virtual environments, players and their physical attractiveness are restricted to small transmission spaces, unlike traditional sports. 
In traditional sports, novelty is a well-known motivation for spectators that can be seen as a driver of eSports consumption as well, confirming Hypothesis 8.

The hypothesis examining the effect of enjoyment of aggressiveness (Hypothesis 9) was rejected ( $\beta=0.166 ; \mathrm{T}=$ 1.10 e $\mathrm{F}^{2}=0.02$ ), contradicting the paper of Hamari and Sjöblom (2017). These authors state that the appreciation of aggressiveness is related to the rivalry between teams of eSports, and not necessarily to aggressiveness itself, as in cases of fighting sports such as boxing and MMA or violent electronic sports genres.

The last analysis concerned social interaction, and the results from Table 3 confirm Hypothesis 10, revealing that social interaction is a driver of eSports, the same way as it happens in the context of traditional sports. Social interaction in eSports community has been a topic of interest of several scholars, indicating as a major motivation for the consumption of this kind of media, showing that digital interaction satisfy the consumer need for socialization (Hamilton et al., 2014; Papacharissi \& Mendelson, 2010; Whiting \& Williams, 2013).

Based on these analyses, Figure 1 reviews the hypotheses elaborated in this work and the results obtained.

Figure 1. Hypothesis Test Results.

\begin{tabular}{|ll|l|}
\hline Hypothesis & Result \\
\hline H1 & Drama drives spectators to consume eSports & Accepted \\
\hline H2 & Vicarious achievement drives spectators to consume eSports & Accepted \\
\hline H3 & Escape drives spectators to consume eSports & Accepted \\
\hline H4 & Acquisition of knowledge drives spectators to consume eSports & Accepted \\
\hline H5 & Esthetics drives spectators to consume eSports & Accepted \\
\hline H6 & Skills of the players/athletes drive spectators to consume eSports & Accepted \\
\hline H7 & Physical attractiveness drives spectators to consume eSports & Rejected \\
\hline H8 & Novelty drives spectators to consume eSports & Accepted \\
\hline H9 & Enjoyment of aggressiveness drives spectators to consume eSports & Rejected \\
\hline H10 & Social interaction drives spectators to consume eSports & Accepted \\
\hline
\end{tabular}

Source: Authors (2021).

The research in eSports fandom is still scarce and this new consumer has not been totally understood from a marketing standpoint, but from this work, it seems that this public presents similar motivations as traditional sports fans. From the ten hypotheses created to understand the motivations of Brazilian eSports consumers, only two of them were rejected, in reference to the constructs physical attractiveness and enjoyment of aggression. Although eight variables are pointed out as positively related to eSports consumption, our findings (see Table 3) reveal four main drivers of this kind of entertainment in Brazil, namely, novelty ( $\beta=0.65)$, escapism ( $\beta=0.67)$, esthetics $(\beta=0.70)$ and vicarious achievement $(\beta=0.71)$. 
Vicarious achievement was the most important driver of eSports motivation, along with esthetics. Thus, we understand that Brazilian spectators and players value the achievements of their teams, resorting to the visual aspects as a relevant issue in their evaluation. Since most of the consumers of this type of this media have below 25 years, age is an important factor, especially because young consumers are influenced by the role of sports celebrities on sales strategies (Dix, Phau, \& Pougnet, 2010; Noble, Haytko, \& Phillips, 2009; Xu, 2008).

When focusing on eSports, Cushen, Rife, and Wann (2019) observed the differences between team or player identification between traditional sports and eSports. Their findings revealed that individuals who exhibit high levels of traditional sports fandom also exhibit high levels of eSports fandom. Given the strong eSports presence in their study, the turnout can attest to the realization of the universal magnitude of traditional sports and how solidified they are in our society.

A big part of eSports content is created by the players itself and this change in content creation also has its effects into the consumers. The well established model of big companies running the show are not well suited for this new spectator, and that is corroborated by the ever-declining viewership of television (McKay, 2018; Katsingris, 2017). Also, the increase of consumption in platforms such as YouTube or Twitch represents this shift in preference (McKay, 2018; Taylor, 2012).

In a sports management context, acquiring supportive information that focuses on consumer identification, motivation, and consumption behaviors within eSports could help stakeholders in the industry better understand which aspect of the product consumers align with. This is important to note for marketing strategies and other tactics such as segmentation, which will help divide the heterogeneous eSports consumer base when pushing marketing initiatives. La Ferle and Chan (2008) demonstrated that culture can lead to significant differences in celebrities' influence over consumers and previous research have shown that consumers' behavior in Latin America, North America and Europe are different (De Onis, 2008; Hitt $\& \mathrm{He}, 2008)$

Finally, considering the purpose of replicating the study from Hamari and Sjöblom (2017) in Brazil, a country wellknown for its relationship with sports, the discussed findings show a relationship between consumers' motivation and eSports media consumption in the context of Brazilian eSports audience. These results configure a first step into identifying the antecedents of eSports consumption antecedents in Brazil, demonstrating consumers' search for entertainment in the form of vicarious achievement and esthetics. In addition, the Brazilian sample does not find motivation in physical attractiveness or aggressiveness, focusing their attention on the enjoyment of the games and the good feelings promoted by the context of players, teams and competition.

\section{Conclusion}

The purpose of this article was to understand the drivers of electronic sports motivation for the Brazilian eSports audience, regarding their motivations to watch and join online matches. We developed a research model composed by ten hypotheses addressing traditional sports motivations to check if they were consistent with the context of eSports. Results indicate that eSports consumption is driven by four main motivations, namely, novelty, escapism, aesthetic and vicarious achievement, being vicarious achievement the main driver of eSports consumption in Brazil.

With respect to the academic contribution of this study, our findings advance the understanding of the influence of culture in eSports consumption, exploring the antecedents of this kind of media entertainment and the role of motivations in the digital arena. This comprehension is paramount due to the increase of digital platforms, digital types of entertainment and the growth of eSports consumption worldwide. Hence, exploring consumer behavior in this context is fundamental, as our discussion may contribute to the comprehension of other marketing variables in this context, such as consumption experience, experience design, advertising and new platforms design and development. 
Concerning managerial implications, the results reported in this article contribute to the development of marketing strategies in this market segment. In this sense, we suggest that an emphasis on esthetics and the visual aspect of eSports, the creation of constant new original offers, the possibility of escape and the role of teams and crowds (vicarious achievement) can lead managers in this sector to better results - more audience, loyalty of the audience and more sponsors, for example.

Regarding the limitations of this research, we address the fact that the answer was collected online in a unique data collection period, raising the question about a possible bias of active users in the online communities. Hence, we suggest that future investigations broaden the scope of the research, covering a longer period with longitudinal studies, in order to understand consumer behavior in season and offseason. A second limitation concerns the research instrument, a scale validated to the context of traditional sports. In this regard, we strongly advise scholars interested in eSports to develop and validate an instrument specific to this segment, which will enable more robust results and relational studies with other marketing and consumer behavior variables.

For future investigation, we suggest scholars should explore the differences in consumption between the genres of eSports, focusing on the possible differences that could emerge from exploring that path. Investigating the consumer experience in live events could also be a fruitful track of research, due to the fact that most of the public of this type of sports are young - this could be an indicator of shift in preferences related to sports consumption. Lastly, we recommend the focus on digital influencers on this type of consumption and the possible insights about how this new industry could be different from traditional sports.

\section{References}

Arnould, E. J., \& Price, L. L. (1993). River magic: Extraordinary experience and the extended service encounter. Journal of Consumer Research, 20 (1), 24-45. $10.1086 / 209331$

Arthur, C., \& Stuart, K. (2014). How Video Gaming Turned in to the World's Newest Spectator Sport. The Guardian. http://www.theguardian. com/technology/2014/aug/30/video-gamesspectator-sport)

Baker, B. J., Zhou, X., Pizzo, A. D., Du, J., \& Funk, D. C. (2017). Collaborative self-study: Lessons from a study of wearable fitness technology and physical activity. Sport management review, 20(1), 114-127. 10.1016/j.smr.2016.10.008

Bányai, F., Griffiths, M. D., Király, O., \& Demetrovics, Z. (2019). The psychology of eSports: A systematic literature review. Journal of gambling studies, 35(2), 351-365. 10.1007/s10899-018-9763-1

Bargh, J. A., \& McKenna, K. Y. (2004). The Internet and social life. Annual Review of Psychology, 55, 573-590. 10.1146/annurev.psych.55.090902.141922

Beranuy, M., Carbonell, X., \& Griffiths, M. D. (2013). A qualitative analysis of online gaming addicts in treatment. International Journal of Mental Health and Addiction, 11(2), 149-161. 10.1007/s11469-012-9405-2

Brislin, R. W. (1970). Back-translation for cross-cultural research. Journal of cross-cultural psychology, 1(3), $185-216$.

Burgess, S. M., \& Steenkamp, J-B. E. M. (2006). Marketing renaissance: How research in emerging markets advances marketing science and practice. International Journal of Research in Marketing, 23(4), 337-356. 10.1016/j. ijresmar.2006.08.001

Cha, J. (2014). Usage of video sharing websites: Drivers and barriers. Telematics and Informatics, 31(1), 16-26. 10.1016/j.tele.2012.01.003

Cheung, G., \& Huang, J. (2011). Starcraft from the stands: Understanding the game spectator. In In Proceedings of the SIGCHI Conference on Human Factors in Computing Systems (pp. 763-772). ACM. 10.1145/1978942.1979053

Chin, W. W. (1998). The partial least squares approach to structural equation modeling. In G. A. Marcoulides (Ed.), Modern methods for business research, 295(2), 295-336.: Lawrence Erlbaum.

Costa Pinto, D., Reale, G., Segabinazzi, R., \& Vargas Rossi, C. A. (2015). Online identity construction: How gamers redefine their identity in experiential communities. Journal of Consumer Behaviour, 14(6), 399-409. 10.1002/cb.1556

Curley, A. J., Nausha, M., Slocum, J., \& Lombardi, D. (2016). What motivates esports fans? A data-driven approach to business and development strategy. Semantic Scholar, 1-11.

Cushen, P. J., Rife, S. C., \& Wann, D. L. (2019). The Emergence of a New Type of Sport Fan: Comparing the Fandom, Motivational Profiles, and Identification of Electronic and Traditional Sport Fans. Journal of Sport Behavior, 42(2).

De Mello, F. C., \& Mastrocola, V. M. (2014). Comunicação, consumo e entretenimento: engajando jogadores de videogame através de recompensas 
simbólicas. Revista Mediação, 16(18), 29-41.

De Onis, J. (2008). Brazil's Big Moment: A South American Giant Wakes Up. Foreign Affairs, 87(6), 110-122.

Desjarlais, M., \& Willoughby, T. (2010). A longitudinal study of the relation between adolescent boys and girls' computer use with friends and friendship quality: Support for the social compensation or the rich-get-richer hypothesis? Computers in Human Behavior, 26(5), 896-905. 10.1016/j.chb.2010.02.004

Dionísio, P., Leal, C., \& Moutinho, L. (2008). Fandom affiliation and tribal behaviour: a sports marketing application. Qualitative Market Research: An International Journal, 11(1), 17-39. 10.1108/13522750810845531

Dix, S., Phau, I., \& Pougnet, S. (2010). "Bend it like Beckham": The influence of sports celebrities on young adult consumers. Young Consumers, 11(1), 3646. $10.1108 / 17473611011025993$

Duncan, M. C., \& Brummett, B. (1989). Types and sources of spectating pleasure in televised sports. Sociology of Sport Journal,6(3), 195-211. $10.1123 / \mathrm{ssj} .6 .3 .195$

Farquhar, L. K., \& Meeds, R. (2007). Types of fantasy sports users and their motivations. Journal of Computer-Mediated Communication, 12(4), 1208-1228. 10.1111/j.1083-6101.2007.00370.x

Ferguson, D. A., \& Perse, E. M. (2000). The World Wide Web as a functional alternative to television. Journal of Broadcasting \& Electronic Media, 44(2), 155-174. 10.1207/s15506878jobem4402_1

Fornell, C., \& Larcker, D. F. (1981). Structural equation models with unobservable variables and measurement error: Algebra and statistics. Journal of Marketing Research, 18(3), 382-388. 10.1177/002224378101800313

Funk, D. C., \& James, J. D. (2006). Consumer loyalty: The meaning of attachment in the development of sport team allegiance. Journal of Sport Management, 20(2), 189-217. 10.1123/jsm.20.2.189

Funk, D., Alexandris, K., \& McDonald, H. (2008). Consumer behaviour in sport and events. Routledge.

Funk, D. C., Pizzo, A. D., \& Baker, B. J. (2018). eSport management: Embracing eSport education and research opportunities. Sport Management Review, 21(1), 7-13. 10.1016/j.smr.2017.07.008

Gandolfi, E. (2016). To watch or to play, it is in the game: The game culture on Twitch. tv among performers, plays and audiences. Journal of Gaming \& Virtual Worlds, 8(1), 63-82. 10.1386/jgvw.8.1.63_1

Goulding, C., Shankar, A., Elliott, R., \& Canniford, R. (2009). The marketplace management of illicit pleasure. Journal of Consumer Research, 35(5), 759771. $10.1086 / 592946$

Griffiths, M. D., Davies, M. N., \& Chappell, D. (2003). Breaking the stereotype: The case of online gaming. CyberPsychology \& Behavior, 6(1), 81-91. $10.1089 / 109493103321167992$

Guttmann, A. (1996). The erotic in sports, Columbia University Press.

Hair, J.F.. Babin, B.. Money, A.H \& Samouel, P. (2003) Essentials of business research methods; United States of America: Johns Wiley \& Sons.

Hair Jr, J. F., Hult, G. T. M., Ringle, C., \& Sarstedt, M. (2016). A primer on partial least squares structural equation modeling (PLS-SEM). Los Angeles, CA: Sage publications.

Hallmann, K., \& Giel, T. (2018). eSports-Competitive sports or recreational activity? Sport management review, 21(1), 14-20. 10.1016/j.smr.2017.07.011

Ham, C. D., Yoon, G., \& Nelson, M. R. (2016). The interplay of persuasion inference and flow experience in an entertaining food advergame. Journal of Consumer Behaviour, 15(3), 239-250. 10.1002/cb.1564

Hamari, J., \& Sjöblom, M. (2017). What is eSports and why do people watch it? Internet research, 27(2), 211-232. 10.1108/IntR-04-2016-0085

Hamilton, W. A., Garretson, O., \& Kerne, A. (2014). Streaming on twitch: fostering participatory communities of play within live mixed media. In Proceedings of the SIGCHI Conference on Human Factors in Computing Systems (pp. 1315-1324). ACM, New York, NY, USA. $10.1145 / 2556288.2557048$

Hanson, G., \& Haridakis, P. (2008). YouTube Users Watching and Sharing the News: A Uses and Gratifications Approach. Journal of Electronic Publishing, 11(3). 10.3998/3336451.0011.305

Heere, B. (2018). Embracing the sportification of society: Defining eSports through a polymorphic view on sport. Sport Management Review, 21(1), 21-24. 10.1016/j.smr.2017.07.002

Hitt, M. A., \& He, X. (2008). Firm strategies in a changing global competitive landscape. Business Horizons, 51(5), 363-369. 10.1016/j.bushor.2008.05.001

James, J. D., \& Ridinger, L. L. (2002). Female and male sport fans: A comparison of sport consumption motives. Journal of Sport Behavior, $25(3)$, p. 260-279.

James, J. D., \& Ross, S. D. (2004). Comparing sport consumer: Motivations across multiple sports. Sport Marketing Quarterly, $13(1)$, 17-25.

Jenny, S. E., Manning, R. D., Keiper, M. C., \& Olrich, T. W. (2017). Virtual (ly) athletes: where eSports fit within the definition of "Sport". Quest, 69(1), 118. 10.1080/00336297.2016.1144517

Jonasson, K., \& Thiborg, J. (2010). Electronic sport and its impact on future sport. Sport in society, 13(2), 287-299. 10.1080/17430430903522996 
Katsingris, P. (2017). The Nielsen Total Audience Report: Q1 2017. https://www.nielsen.com/us/en/insights/report/2017/the-nielsen-total-audience-report-q12017/\#

Kim, S. J., Choi, Y. K., Kim, K. H., \& Liu, H. (2015). Country of origin and brand image influences on perceptions of online game quality. Journal of Consumer Behaviour, 14(6), 389-398. 10.1002/cb.1554

Kline, R. B. (2011). Principles and practice of Structural equation modeling. Guilford.

La Ferle, C., \& Chan, K. (2008). Determinants for materialism among adolescents in Singapore. Young Consumers, 9(3), 201-214. $10.1108 / 17473610810901633$

Mangeloja, E. (2019). Economics of ESports. Electronic Journal of Business Ethics and Organization Studies, 24(2), 34-42.

Mazalin, D., \& Klein, B. (2008). Social anxiety and the Internet: Positive and negative effects. Sensoria: A Journal of Mind, Brain \& Culture, 4(2), 43-50.

McKay, B. (2018). The future of media buying: YouTube versus traditional TV. Forbes. https://www.forbes.com/sites/forbesagencycouncil/2018/01/16/thefuture-of-media-buying-youtube-versus-traditional-tv/\#375157342675

Miller, V. (2011). Understanding digital culture. Sage Publications.

Milne, G. R, \& McDonald, M. A. (1999). Sport Marketing: managing the exchange process. Jones and Bartlett Publishers.

Molesworth, M., Watkins, R., \& Denegri-Knott, J. (2016). Possession work on hosted digital consumption objects as consumer ensnarement. Journal of the Association for Consumer Research, 1(2), 246-261. 10.1086/685474

Newzoo. (2020). Newzoo Global ESports Market Report 2020.

Noble, S. M., Haytko, D. L., \& Phillips, J. (2009). What drives college-age generation Y consumers? Journal of Business Research, 62(6), 617-628. 10.1016/j.jbusres.2008.01.020

Papacharissi, Z., \& Mendelson, A. (2010). Toward a new(er) sociability: uses, gratifications and social capital on Facebook. In S. Papathanassopoulos (Ed.), Media perspectives for the 21 st century pp.593-628. New York, NY:Routledge.

Peterson, E. M., \& Raney, A. A. (2008). Reconceptualizing and reexamining suspense as a predictor of mediated sports enjoyment. Journal of Broadcasting \& Electronic Media, 52(4), 544-562. 10.1080/08838150802437263

Pine, B. J., Pine, J., \& Gilmore, J. H. (1999). The experience economy: Work is theatre \& every business a stage, Harvard Business Press.

Pine, B. J., \& Gilmore, J. H. (2013). The experience economy: past, present and future. In J. Sundbo \& F. Sørensen (Eds.), Handbook on the experience economy pp.21-44. Northampton, MA: Edward Elgar Publishing.

Pizzo, A. D., Na, S., Baker, B. J., Lee, M. A., Kim, D., \& Funk, D. C. (2018). eSport vs. Sport: A Comparison of Spectator Motives. Sport Marketing Quarterly, 27(2), 108-123.

Quilliam, E. T., Lee, M., Cole, R. T., \& Kim, M. (2011). The impetus for (and limited power of) business self-regulation: the example of advergames. Journal of Consumer Affairs, 45(2), 224-247. 10.1111/j.1745-6606.2011.01201.x

Raney, A. A. (2006). Why we watch and enjoy mediated sports. In A. A. Raney \& J. Bryant (Eds.). Handbook of sports and media pp.313-340. Routledge.

Raney, A. A., \& Depalma, A. J. (2006). The effect of viewing varying levels and contexts of violent sports programming on enjoyment, mood, and perceived violence. Mass Communication \& Society, 9(3), 321-338. 10.1207/s15327825mcs0903_4

Robinson, M. J., Trail, G. T., \& Kwon, H. (2004). Motives and points of attachment of professional golf spectators. Sport Management Review, 7(2), 167-192. $10.1016 / \mathrm{S} 1441-3523(04) 70049-2$

Robinson, M. J., \& Trail, G. T. (2005). Relationships among spectator gender, motives, points of attachment, and sport preference. Journal of Sport management, 19(1), 58-80.10.1123/jsm.19.1.58

Rubin, A. M. (1994). Media uses and effects: A uses-and-gratifications perspective. In J. Bryant \& D. Zillmann (Eds.), LEA's communication series. Media effects: Advances in theory and research pp. 417-436. Hillsdale, MI: Lawrence Erlbaum Associates.

Rubin, A. M. (2009). Uses and gratifications: An evolving perspective of media effects. In R. L. Nabi \& M. B. Oliver (Eds.). The SAGE handbook of media processes and effects pp.147-159. Los Angeles, CA: SAGE Publications.

Ruggiero, T. E. (2000). Uses and gratifications theory in the 21st century. Mass communication \& society, 3(1), 3-37. 10.1207/S15327825MCS0301_02

Scholz, T. M. (2012, December). New broadcasting ways in IPTV-The case of the Starcraft broadcasting scene. Conference paper in World media economics \& management conference. Thessaloniki, Greece.

Seo, Y. (2013). Electronic sports: A new marketing landscape of the experience economy. Journal of Marketing Management, 29(13-14), 1542-1560. $10.1080 / 0267257 X .2013 .822906$

Seo, Y. (2016). Professionalized consumption and identity transformations in the field of eSports. Journal of Business Research, 69(1), 264-272. 10.1016/j.jbusres.2015.07.039

Seo, W. J., \& Green, B. C. (2008). Development of the motivation scale for sport online consumption. Journal of Sport Management, 22(1), 82-109. $10.1123 /$ jsm.22.1.82 
Seo, Y., \& Jung, S. U. (2016). Beyond solitary play in computer games: The social practices of eSports. Journal of Consumer Culture, 16(3), 635-655. $10.1177 / 1469540514553711$

Shao, G. (2009). Understanding the appeal of user-generated media: a uses and gratification perspective. Internet Research, 19(1), 7-25. $10.1108 / 10662240910927795$

Sheth, J. N. (2011). Impact of emerging markets on marketing: Rethinking existing perspectives and practices. Journal of marketing, 75(4), 166-182. 10.1509/jmkg.75.4.166

Sjöblom, M., Macey, J., \& Hamari, J. (2019a). Digital athletics in analogue stadiums: Comparing gratifications for engagement between live attendance and online eSports spectating. Internet Research, 30(3), 713-735. 10.1108/INTR-07-2018-0304

Sjöblom, M., Törhönen, M., Hamari, J., \& Macey, J. (2019b). The ingredients of Twitch streaming: Affordances of game streams. Computers in Human Behavior, 92, 20-28. 10.1016/j.chb.2018.10.012

Skandalis, A., Byrom, J., \& Banister, E. (2019). Experiential marketing and the changing nature of extraordinary experiences in post-postmodern consumer culture. Journal of Business Research, 97, 43-50. 10.1016/j.jbusres.2018.12.056

So, J. (2012). Uses, gratifications, and beyond: Toward a model of motivated media exposure and its effects on risk perception. Communication Theory, 22(2), 116-137. 10.1111/j.1468-2885.2012.01400.x

Southern, N. (2017). The rise of eSports: A new audience model and a new medium? BA Camdidate, Department of Mathematics, California State University Staniaslaus, 1 University Circle, Turlock, CA, 95382, 65-68.

Sullivan, D. B., Raney, A. A., \& Bryant, J. (2006). Broadcast television and the game of packaging sports. In A. A. Ran ey \& J. Bryant (Eds.), Handbook of sports and media pp.131-145. Lawrence Erlbaum.

Taylor, T. L. (2012). Raising the Stakes: ESports and the Professionalization of Computer Gaming. Mit Press.

Taylor, T. L. (2018). Watch me play: Twitch and the rise of game live streaming. Princeton University Press.

Trail, G. T., Anderson, D. F., \& Fink, J. S. (2000). A theoretical model of sport spectator consumption behavior. International Journal of Sport Management, 1(3), 154-180.

Trail, G. T., \& James, J. D. (2001). The Motivation Scale for Sport Consumption: A Comparison of Psychometric Properties with other Sport Motivation Scales. Journal of Sport Behavior, 24(1), 108-127.

Trail, G. T. (2012). Manual for the motivation scale for sport consumption (MSSC). Center for Sport Consumer Research, 1-9. http://sportconsumerresearchconsultants.yolasite.com/resources/MSSC\%20Manual\%20-\%202012.pdf

Valkenburg, P. M., \& Peter, J. (2009). Social consequences of the Internet for adolescents: A decade of research. Current directions in psychological science, 18(1), 1-5. 10.1111/j.1467-8721.2009.01595.x

Vanwesenbeeck, I., Ponnet, K., \& Walrave, M. (2016). Go with the flow: How children's persuasion knowledge is associated with their state of flow and emotions during advergame play. Journal of Consumer Behaviour, 15(1), 38-47. 10.1002/cb.1529

Xiao, M. (2020). Factors influencing eSports viewership: An approach based on the theory of reasoned action. Communication \& Sport, 8(1), 92-122. $10.1177 / 2167479518819482$

$\mathrm{Xu}, \mathrm{Y}$. (2008). The influence of public self-consciousness and materialism on young consumers' compulsive buying. Young consumers, 9(1), 37-48. $10.1108 / 17473610810857309$

Wang, Q., Fink, E. L., \& Cai, D. A. (2008). Loneliness, gender, and parasocial interaction: A uses and gratifications approach. Communication Quarterly, 56(1), 87-109. 10.1080/01463370701839057

Wann, D. L., Allen, B., \& Rochelle, A. R. (2004). Using sport fandom as an escape: Searching for relief from under-stimulation and overstimulation. International Sports Journal, 8(1), 104-113.

Weed, M. (2006). Sports tourism and the development of sports events. Idrottsforum. org, December, 13.

Weiss, T., \& Schiele, S. (2013). Virtual worlds in competitive contexts: Analyzing eSports consumer needs. Electronic Markets, 23(4), 307-316. $10.1007 / \mathrm{s} 12525-013-0127-5$

West, R. L., \& Turner, L. H. (2006). Introducing communication theory: Analysis and application. McGraw-Hill Humanities/Social Sciences/Languages.

Whiting, A., \& Williams, D. (2013). Why people use social media: a uses and gratifications approach. Qualitative Market Research. 16(4), 362-369. 10.1108/QMR-06-2013-0041

Woermann, N., \& Kirschner, H. (2015). Online livestreams, community practices, and assemblages. Towards a site ontology of consumer community. Advances in Consumer Research, 43, 438-442.

Wohn, D. Y., \& Freeman, G. (2020). Live Streaming, Playing, and Money Spending Behaviors in eSports. Games and Culture, 15(1), 73-88. $10.1177 / 1555412019859184$

Won, J. U., \& Kitamura, K. (2007). Comparative Analysis of Sport Consumer Motivations between South Korea and Japan. Sport Marketing Quarterly, 16(2). 
Research, Society and Development, v. 10, n. 5, e40710515188, 2021

(CC BY 4.0) | ISSN 2525-3409 | DOI: http://dx.doi.org/10.33448/rsd-v10i5.15188

Wu, J. H., Wang, S. C., \& Tsai, H. H. (2010). Falling in love with online games: The uses and gratifications perspective. Computers in Human Behavior, 26(6), 1862-1871. 10.1016/j.chb.2010.07.033

Yu, B., Bennett, G., \& Brison, N. (2019). Comparing Gender Consumption Motives of eSports Fans. Sports Marketing Association Conference Proceedings.

Yuan, D., Lin, Z., \& Zhuo, R. (2016). What drives consumer knowledge sharing in online travel communities?: Personal attributes or e-service factors? Computers in Human Behavior, 63, 68-74. 10.1016/j.chb.2016.05.019

Zhou, J., Zhou, J., Ding, Y., \& Wang, H. (2019). The magic of danmaku: A social interaction perspective of gift sending on live streaming platforms. Electronic Commerce Research and Applications, 34, 100815. 10.1016/j.elerap.2018.11.002

Zhu, D. H., \& Chang, Y. P. (2014). Understanding motivations for continuance intention of online communities in China: A comparison of active users of social networking sites and virtual communities. Information Development, 30(2), 172-180. 10.1177/0266666913482597 